\title{
Memória
}




\section{A escuta do pacto e da Grande Prece dos confederados}

JEAN STAROBINSKI

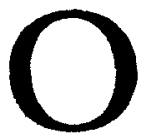

pacto de 1291 renova e confirma os elos preexistentes: declara-os válidos "para sempre". Esse texto náo é somente uma convençăo jurídica fundamental: $t$ um grande documento sobre a natureza das relaçóes humanas e sobre o que transforma a palavra - o verbo escrito, assinado, selado - em um ato. Eis o que sabiam os homens de 1291, por um conhecimento imediato do qual tiveram a coragem de tirar as conclusóes: os homens são violentos e é necessário ultrapassar a violência. Não é ignorando a violência que ela será superada, mas tomando contra ela todas as medidas apropriadas. Para repelir o assalto dos violentos, contra impetus malignorum, é necessário começar por ajudar-se mutuamente na resistência. Mas a violência interna não é menos temível que a agressão vinda de fora. Os contratantes de 1291 tomam medidas comuns a todos contra os assassinos e os incendiários. Eles prevêem, entre as três comunidades, o risco de conflitos de interesses. Esses litígios não deverão ser julgados por juízes estrangeiros. Para prevenir a dissensáo brutal, faz-se um apelo à mediação e à arbitragem. Ensteht ein Streit unter Eidgenossen, so sollen die Einsichtigsten unter ibnen vermitteln (1). Estando enunciado o princípio, um longo aprendizado estava por se fazer, nas atribulaçóes da história. O passado da Suíça nada tem de idílico. Excesso e desavenças não foram evitados. Mas o princípio da arbitragem se manteve. Hoje vivemos em uma Europa onde ressurgem conflitos interétnicos, em um mundo onde os nacionalismos regionais ou tribais náo cessam. Ora, os suíços aprenderam a difícil arte de conviver, no respeito de suas diferenças. Essa experiência se materializou nas instituiçóes e estas podem oferecer, se não um modelo a ser literalmente copiado, pelo menos a indicaçáo de uma via a seguir $\mathrm{c}$, consequientemente, um motivo de esperança para outros que não nós. O federalismo $\epsilon$, certamente, um sistema viável. Denis de Rougemont, entre outros, disse-o com veemência.

Um quadro famoso de Johann-Heinrich Füssli retrata as três Suígas em um grande ímpeto voluntário, os braços levantados, simbolizando o ato fundador mítico e, sobretudo, o apelo a Deus pelo qual começa o 
pacto. Mas o texto do pacto não esquece que os homens, e mesmo aqueles que prestam juramento, sáo seres imperfeitos, falíveis, que devem ser contidos pela fé jurada. É um texto ao mesmo tempo audacioso e de uma singular humildade. Ser humilde e reunir suas forças para impedir o avanço do invasor não săo coisas incompatíveis.

No fim da Idade Média, por ocasiáo de uma guerra ou para comemorar os mortos de uma batalha (a de Sempach, principalmente, ou a de Arbedo), grupos de homens e mulheres, revezando-se às vezes de aldeia em aldeia, recitavam a Grande Prece; esta começava, de maneira cristá, por um ato de contriçáo. Em uma das versóes do Grosses Gebet der Eidgenossen, lế-se:

" Erstlich soll cin jeglicher Mensh sich selbst erkennen wegen seiner Sünden und Missethgten, die or wider Gott unsern Herrn gethan bat und festiglich fürsetzon, uns zu bütern vor Sünden und Gelegenbeiten dor Siinden..." (2)

Essas palavras de arrependimento, esse confiteor, não as considero como uma simples fórmula de precauça destinada a conquistar a proteçáo divina. Como em Davi, o rei salmista, a coragem da confissáo dos pecados náo é diferente da coragem para ó combate. É reconhecer uma condiçáo finita, imperfeita, é aceitar não depender unicamente de seu próprio julgamento. E quando falo de combate, náo penso somente nos feitos de armas dos primeiros séculos: penso em qualquer grande projeto, penso em qualquer empresa de envergadura. Náo se ater unicamente a seu desejo pessoal, aceitar ser responsável por seus atos perante os outros ou perante um Outro, tal t́ sem dúvida a melhor definiçáo do sentido da responsabilidade. E bom lembrar as palavras da Grande Prece. Pois o orgulho nos prepara uma armadilha: à complacência consigo mesmo, primeiramente, que a língua alemá denomina táo bem Selbstgefalligheit: é a preguiça de espírito que consiste em crer que cumprimos escrupulosamente tudo o que nos foi pedido e que todo questionamento $\epsilon$ inútil. $E$ a outra armadilha $\epsilon o$ ressentimento reivindicador, que o alemão exprime com precisão pela noção de Selbstgerechtigkeit: é a atitude dos pássaros de mau agouro, que se acreditam puros e sem mácula porque denunciam as faltas dos outros. Essas atitudes, uma tão errônea quanto a outra, são próprias das comunidades que atingiram um certo bem-estar. Elas sáo, tanto uma quanto a outra, paralisantes: são luxos perniciosos. Duas maneiras de nos esquivarmos de nossas responsabilidades. Eu desejo que nosso país náo se imobilize nem na consciência limpa nem na consciência pesada. Que ele tenha a coragem de uma grande ambição, sem esquecer a virtude da humildade. Pois é necessário ser humilde para ter vontade de superar-se, e para desejar responder 
cada vez melhor, na vida quotidiana e dentro das leis, às exigenncias da ética e do mais lato interesse comum.

Permito-me insistir: a verdadeira liberdade política, a liberdade mais bem compartilhada é apanágio das sociedades que reconhecem que os indivíduos não devem ter a permissāo de fazer o que bem entenderem e que o prazer desenfreado não é a autoridade decisiva. Esse sentido das proporçóes, essas limitaçóes legais; a recusa do arbitrário, exigidos pelo respeito ao próximo, não vamos considerá-los como uma prisáo! Náo, decididamente, irei buscar fora da Suíça, na história do século XX, os exemplos do confinamento e da servidāo voluntária!

Lê-se com emoçăo, na Grande Prece, um dos últimos pedidos:

"Wir wollen auch bitten für diejbenigen, so allenthalben Steg und Weg bessern, auch mit ibren Unkosten und Arbeit, so wol Geistlich als Leiblich, den gemeinen Nutzen treuwlich befuirdem helffen...."(3)

Outra versáo acrescenta: "Und die grachtikbeid lib babend" (4).

Sim, celebremos o obscuro, o glorioso trabalho dos que aperfeiçoam atalhos e caminhos! Penso nos atalhos das pastagens alpinas, como nos caminhos de peregrinação. Penso em todas as estradas essenciais conservadas para o bem comum: nos velhíssimos caminhos de mulas que atravessavam os Alpes, assegurando o intercâmbio entre o Norte e o Sul, e que necessitavam de uma escolta de fortalezas. Estamos apoiados em um deles.

Os que melhoravam atalhos e caminhos colocavam ao serviço da Europa cisalpina e da Itália (com seus parceiros orientais) os grandes eixos do comércio e da cultura. Vêm-me primeiramente à mente os pintores alemães ou flamengos a caminho de Veneza ou Roma, que descobriram os primeiros fogos da luz meridional sobre o flanco dos Alpes, no cintilar dos rochedos e cascatas. Esses caminhos bordejavam freqüientemente os grandes rios cuja linha de divisa se situa nos pontos centrais de nosso maciço alpino. Os que alargaram e consolidaram essas vias imemoriais prepararam a Suíça para sua função de mediadora e de receptora. Foram, no tempo do humanismo, os caminhos da vagabundagem dos estudantes que foram aprender as letras nos quatro cantos da Europa, como o fez o pequeno pastor de cabras do cantáo de Valais, Thomas Plater. Não acabaríamos mais, também, se evocássemos os que tomaram a estrada para procurar de que viver em terra estrangeira: arquitetos e estucadores do cantáo de Tessin, doceiros de Engadina e do Vale de Bregaglia. Pelas mesmas estradas partiram soldados do Serviço Estrangeiro, levando saudade da pátria no coraçāo. Em sentido inverso 


\section{1 - 1991 Suíça}

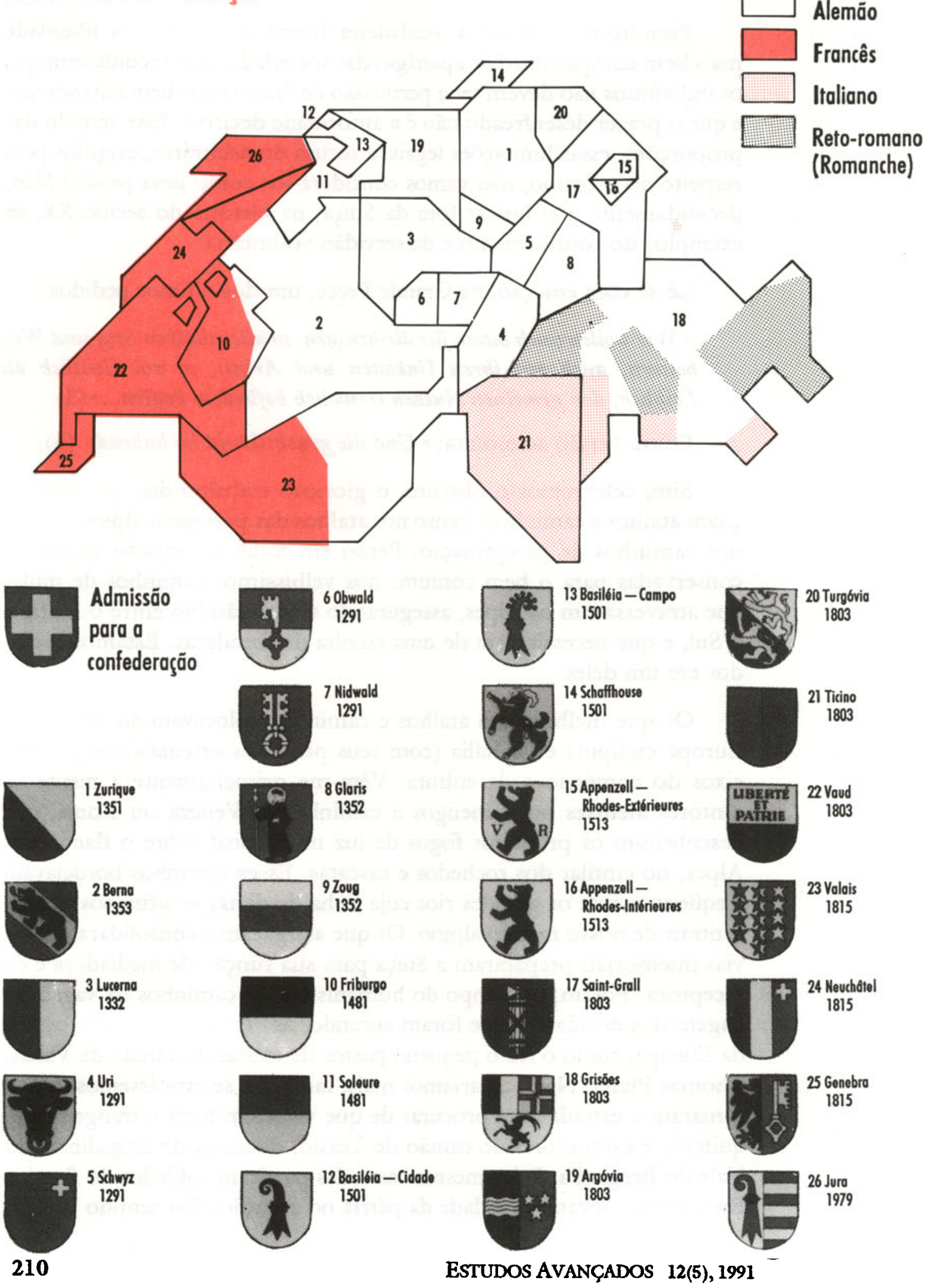




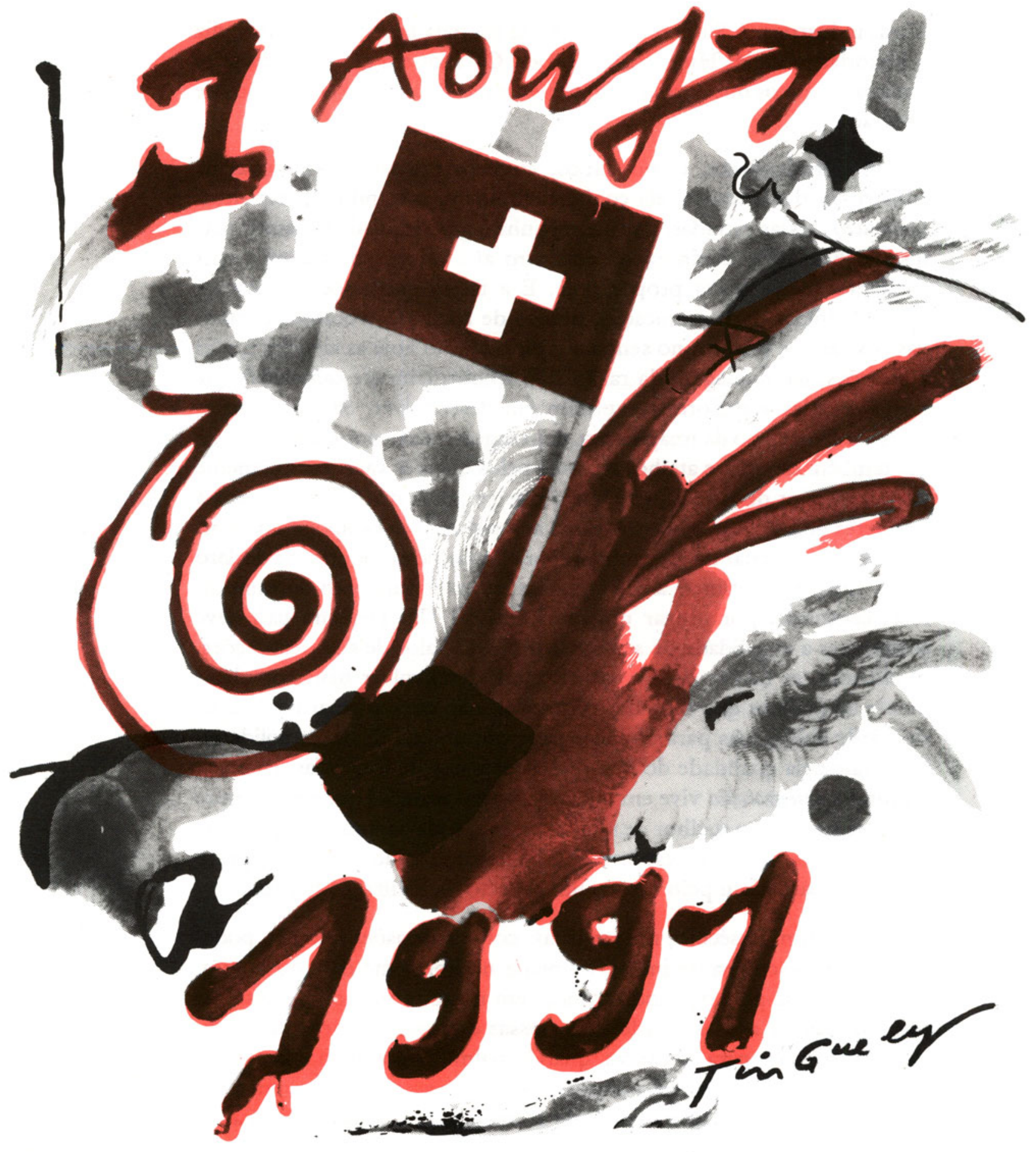

Criação de Jean Tinguely

Arte: Carla A. Risso editada pelo Conselho do Cantão de Vaud, em comemoraçáo do 700 aniversário da Confederaf̧áo Helvética 
- da França, de Flandres, da Itália - afluíram os que buscavam refúgio por motipos religiosos. Erasmo em Basiléia, os Estienne em Genebra. Eles vieram, esses huguenotes, esses hereges, estabelecer e fazer prosperar novas indústrias. A Sưça do século XVII foi feita pelos estrangeiros, diz - historiador ingles Hug Trevor Roper. Os anos em que as estradas se fecharam para os que corriam um perigo mortal imediato foram anos de desgraça.

A Grande Prece, como vimos, conhece um sentido material da construçäo das estradas; ela conhece, também, o significado espiritual (goistlich) dessas estradas, que acompanha a generosidade 00 amor pela justiça. Essa idéia é admirável: encontro aí a expressão da tarefa mais exaltante que se possa propor hoje. É a tarefa que associa educaçáo, cultura, ofícios da comunicaçáo, ofícios de recepçáo, vocaçóes caritativas. Estradas e atalhos, no sentido espiritual, são hoje as ciencias e suas aplicaçōes, na linguagem da razão (tấo freqüentemente caluniada) que nossas escolas superiores se aplicam em desenvolver. São tambem as artes e o livre curso da imaginaçáo, cujo esgotamento nos empobreceria. Há também estradas $\mathrm{e}$ atalhos secretos pelos quais se vai silenciosamente para o interior de si mesmo. Desejo que se possa dizer, dos homens e mulheres de hoje, que contribuíram cada um em seu campo, e nos mais modestos, para criar novas estradas, para lançar novas pontes. Se declaro que $\boldsymbol{\epsilon}$ urgente continuar a distinguir-se no maior número de campos, serei censurado por pregar um ideal elitista? Um pequeno país deve compensar a exigüidade de seu território pelo valor de suas realizaçóes. O elitismo, se tal for o caso, consiste em desenvolver mais completamente os poderes que cada um traz $\mathrm{cm}$ si, não para afirmar uma superioridade altiva, mas para ter mais para comunicar. $O$ ato de solidariedade vale pela qualidade do que oferecemos aos de fora. Mas, eu o sei, - mundo deservolvido vive em uma civilizaçáo material que nem sempre encoraja a atingir o melhor de si. Ela reserva, todavia, uma exceçáo mais que meritória: o esforço esportivo, o belo domínio do corpo e do gesto que salvaguardariam pelo menos um aspecto da realizaçáo humana.

Neste fim de século, nossas vidas, com as decisóes que náo podemos evitar, inscrevem-se inelutavelmente no horizonte da terra inteira. Mas o caminho para o mundo comega em nossa porta, sob nossos passos, nas ruas de nossas cidades, em nossas estaçóes. Começa, também, quando partimos para as alturas, quando palmilhamos atalhos cheios de trevos e escabiosas, quando atravessamos o riacho sobre as pranchas ajustadas pelo cantoneiro, quando saudamos o desconhecido que passa. E se seguirmos o convite do atalho, nāo será necessário muito tempo para redescobrir - a cada manhá como se fosse a primeira vez - que 
somos os depositários de uma parte muito preciosa da beleza do mundo. Sentimos mais do que nunca quanto essa beleza é vulnerável. A Grande Prece falava do amor pela justiça. Sim, saibamos fazer justiça ao campo de trigo, às vinhas $\mathrm{e}$ ao pomar, à floresta $\mathrm{e}$ à geleira, que sáo nossos primeiros interlocutores: entăo, somente, teremos aprendido a oferecer uma melhor amizade ao mundo longínquo, a responder-the e a the fazer o sinal, que ele espera certamente, de uma presença eficaz e de uma preocupaçáo conjunta com a paz entre os homens.

Bellinzona, 10 de janeiro de 1991.

Citaçōes de Peter Ochsenbein, Das Grosse Gebet der Eidgenossen, Francke Verlag, Berne, 1989.

\section{Notas}

1 Trad.: "Se alguma discordia vier a surgir entre os confederados, os mais prudentes interviráo por arbitragem para aplacar a desavença."

2 Trad.: "Em primeiro lugar, cada um, voltando-se para si mesmo, deve reconhecer seus pecados e seus malfeitos, que tiver cometido contra Deus, e tomar a firme resoluçāo de guardar-se dos pecados e das ocasióes de pecado."

3 Trad.: "Queremos mmbem orar por aqueles que em qualquer lugar melhoram caminhos e atalhos, a suas custas tambem, e al colocando seu esforço, tanto espiritualmente quanto materialmente, e que servem fielmente o bem comum."

4 Trad.: "E que amam a justiça."

Jean Starobinski é teórico e crítico literário suíço. Professor da Universidade de Genebra. Entre seus vários livros, destacam-se o clássico Jean-Jacques Roussenu: la transparence ot l'obstacle (1957) e, já publicados no Brasil, As palavras sob as palapras: os anagramas de Ferdinand de Saussure (1974, Perspectiva), 1789: os emblemas da razdo (1989, Companhia das Letras) e Montesquieu (1990, Companhia das Letras).

Tradução de Isabel Rupaud. Revisão de Jacques Marcovitch.

O original em francês encontra-se à disposiçăo do leitor no IEA-USP para eventual consulta. 